\title{
Method of determination of palladium concentration for C-Pd nanostructural films as a function of film thickness, roughness and topography
}

\author{
JOANNA RYMARCZYK*, MiROSŁAW KOZŁOWSKI \\ Tele \& Radio Research Institute, Ratuszowa 11, 03-450 Warsaw
}

\begin{abstract}
In this paper a method of determination of $\mathrm{Pd}$ in a carbon-palladium film (C-Pd film) deposited on a quartz substrate is presented. This method is based on energy dispersive X-ray spectroscopy (EDX) and all experiments were performed using a scanning electron microscope (SEM) equipped with EDX system. Qualitative and quantitative analyses were carried out for C-Pd films prepared by PVD method in different technological conditions. It was shown that results of the experiments depended on the structural model, film thickness and electron beam energy used for Pd content calculation.

This method enabled us to conclude on the homogeneity of palladium distribution in the whole volume of carbonaceous matrix, depending on the parameters of PVD process. Additionally, these studies showed that a different palladium concentration in C-Pd films had a significant impact on their topography and morphology.
\end{abstract}

Keywords: palladium; carbon; SEM; EDX

(C) Wroclaw University of Technology.

\section{Introduction}

Palladium is an element which exhibits strong sorption properties compared to hydrogen. Hydrogen absorption by palladium leads to formation of palladium hydride in gaseous environment. The resulting compounds are characterised by poor stability and good reversibility [1-4]. Different carbon nanomaterials also react to gas containing hydrogen with different concentrations. For carbonpalladium films it can be assumed that $\mathrm{C}-\mathrm{Pd}$ films exhibit combined sorption properties of palladium and carbon in various allotropic forms in hydrogen-containing gaseous environment. Studies conducted so far indicate that the reactivity of C-Pd films to hydrogen and its compounds depends on palladium content in the film which mostly varies depending on the PVD process by which such films are obtained. The results of our study suggest that the reactivity of C-Pd films to hydrogen and its compounds depends on palladium content in the

*E-mail: joanna.rymarczyk@itr.org.pl film as a result of the technological conditions during the PVD process by which the films have been obtained [5-7].

Quantitative and qualitative analyses of the composition of C-Pd films obtained under different process technological conditions were carried out using scanning electron microscopy and X-ray spectrometry. Scanning electron microscope with field emission is one of the most popular instruments used for determining parameters of thin films and layers. The great advantage of this type of microscope is the capability of operating at very low accelerating voltages (less than $2 \mathrm{kV}$ ) with a high resolution of $1.5 \mathrm{~nm}$. Thus, it is possible to study a surface morphology with low roughness which is not possible in the case of conventional scanning electron microscope with tungsten cathode [8].

In our previous studies, the analysis of the Pd content was performed by atomic absorption spectroscopy (AAS) with a monochromatic lamp at $232 \mathrm{~nm}$. The films were dissolved in toluene and then dried. The dry powder was used to pre- 
pare a solution based on $\mathrm{HNO}_{3}$. This solution was again dried and the resulting powder was used for AAS analysis. The disadvantage of this method is destruction of the film. Additionally, using this method we get an averaged result, without any information about the morphology of the layer. The correct designation of palladium content is important in terms of properties of the C-Pd films. On the basis of the knowledge of the film composition it can be inferred about reactivity of hydrogen.

\section{Experimental details}

Composite C-Pd films described in this paper were obtained by PVD process based on thermal evaporation of two starting materials, fullerene $\left(\mathrm{C}_{60}\right)$ and palladium acetate, placed in separate containers and heated resistively to temperatures corresponding to their melting points. The processes were carried out in dynamic vacuum $\left(10^{-3} \mathrm{~Pa}\right)$ so as to enable deposition of the starting materials in gaseous form on the quartz substrate placed at a distance of $\mathrm{d}=60 \mathrm{~mm}$ from the source. Different melting points of palladium acetate and fullerene and differences in vapour condensation and crystallization give rise to films of different structural topography and morphology [9]. As a result of the partial decomposition of fullerene and palladium acetate, a nanocomposite film of $\mathrm{Pd}$ nanocrystals embedded in a carbonaceous matrix is formed. The matrix is composed of amorphous carbon [10].

The technological parameters of preparation of C-Pd films, as discussed in this article, are shown in Table 1. whole surface.

The topography and composition of the PVD films were studied by field emission scanning electron microscopy (SEM) (JEOL-JSM 7600F) with Schottky cathode working at an accelerating voltage of $0.1-30 \mathrm{kV}$. The beam current of the microscope obtained using a new FEG hot cathode was very stable $(0.8 \% / 8 \mathrm{~h})$ which was very important when performing quantitative analysis. In addition, the microscope was equipped with energydispersive X-ray spectroscope (INCA250, Oxford). It was possible to carry out qualitative and quantita- tive analyses in micro-areas for such elements from $\mathrm{B}$ to $\mathrm{U}$. Thus, it was possible to determine the percentage of palladium in the $\mathrm{C}-\mathrm{Pd}$ film.

Quantitative and qualitative analyses of the C-Pd films were carried out in the following conditions:

- accelerating voltage: 4, 7, 10 and $15 \mathrm{kV}$;

- beam current value adjusted so that the dead time was within the optimum range of $20 \div 40 \%$;

- time of a single measurement: $50 \mathrm{~s}$;

- surface area of the measurement: $10 \times 20 \mu \mathrm{m}$;

- number of measurements per accelerating voltage: 10 ;

- working distance (WD): $15 \mathrm{~mm}$.

\section{SEM and EDX test results}

The SEM images for the C-Pd films obtained by PVD process are shown in Fig. 1. The previous studies showed that C-Pd films were composed of palladium nanograins embedded in carbonaceous matrix. The palladium nanograins had a diameter of a few nanometers [10] and were invisible on the SEM images. In the images formed by secondary electrons, surface topography is the source of contrast. SEM images show that all samples have different topography. For the film 1 (Fig. 1a), which is very smooth, the contrast derived from grain boundary carbon-palladium is minimal, and therefore the image does not show any explicit details. The surface roughness of Sample 1 is very low. Due to the low contrast of the SEM image, it was not possible to carry out an accurate measurements of the size of particles forming film 1 .

The SEM image of the surface of Sample 2 (Fig. 1b) shows the clusters of carbon-palladium grains. This film is characterized by much greater surface roughness than film 1, and therefore, its topographic contrast is significantly higher. The dark boundaries separating particular carbon-palladium grain clusters can be clearly distinguished. This agglomerates have a diameter of $100-200 \mathrm{~nm}$.

Sample 3 has the most developed surface. SEM image (Fig. 1c) shows that the film is built of grains 
Table 1. Technological parameters of PVD process.

\begin{tabular}{|c|c|c|c|c|c|}
\hline \multirow[t]{2}{*}{ Sample } & \multicolumn{2}{|c|}{$\begin{array}{l}\text { Intensity of } \\
\text { evaporation }\end{array}$} & \multirow{2}{*}{$\begin{array}{c}\text { Time } \\
\mathbf{t}[\mathrm{min}]\end{array}$} & \multirow{2}{*}{$\begin{array}{c}\text { Distance from the } \\
\text { sources to the substrates } \\
\text { d [mm] }\end{array}$} & \multirow[t]{2}{*}{ Substrate } \\
\hline & $\overline{\mathbf{I}_{\mathbf{C 6 0}}[A}$ & Pd $[\mathbf{A}]$ & & & \\
\hline Sample 1 & 1.8 & 1.2 & 10 & 60 & quartz \\
\hline Sample 2 & 1.9 & 1.1 & 10 & 60 & quartz \\
\hline Sample 3 & 2.0 & 1.1 & 10 & 60 & quartz \\
\hline
\end{tabular}

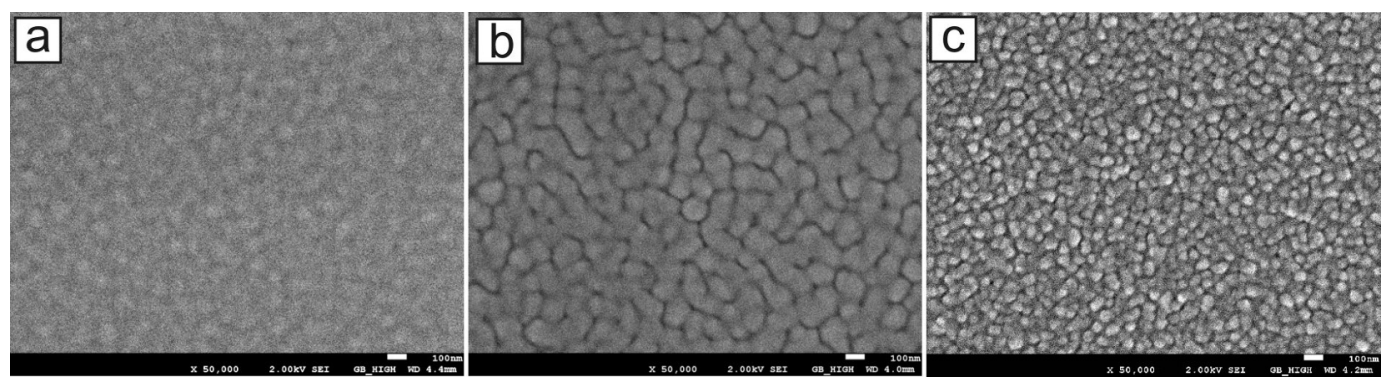

Fig. 1. SEM images (a) Sample 1; (b) Sample 2; (c) Sample 3

with sharp edges with diameters of $50-100 \mathrm{~nm}$. C-Pd grains are smaller than in Sample 2, clearly separated and covering the whole surface.

The qualitative and quantitative analyses of the C-Pd films were carried out by EDX method at different accelerating voltages. The minimum accelerating voltage, and thus the incident electron energy, must be such that it could excite all the elements included in the film. It must be greater than the critical excitation energy of the X-ray line elements in the film. With the optimum excitation conditions, the incident electron energy $\left(\mathrm{E}_{0}\right)$ should be greater than the maximum excitation energy of the $\mathrm{X}$-ray lines $\left(\mathrm{E}_{c}\right)$ of the film. For tests to be carried out at low energies of incident electrons (low accelerating voltage), the overvoltage may be $\mathrm{E}_{0} / \mathrm{Ec}>1.1$ [11].

As concluded from the EDX spectra analysis, the C-Pd films are composed of carbon, oxygen (K-series peaks) and palladium (Lseries peaks) [12]. $E_{c}$ values for the elements contained in the C-Pd films are as follows: $\mathrm{E}_{c}(\mathrm{CK} \alpha)=0.277 \mathrm{keV}, \mathrm{E}_{c}(\mathrm{OK} \alpha)=0.525 \mathrm{keV}$, $\mathrm{E}_{c}(\mathrm{PdL} \alpha)=2.838 \mathrm{keV}$. In the case of C-Pd films, the greatest value of $\mathrm{E}_{c}$ has a $\operatorname{PdL} \alpha$ line, so that the value of $E_{0} / E_{c}=4 / 2.838=1.41$ is perfectly acceptable. This means that the voltage of $4 \mathrm{kV}$ is suitable for reliable quantitative analysis of our samples.

Fig. 2 - 4 show the EDX spectra recorded for C-Pd films at different accelerating voltages. For the voltage of $4 \mathrm{kV}$ the spectra show the peaks of the C-Pd films which were slightly oxidized. The peak of the substrate $\left(\mathrm{SiO}_{2}\right)$ is not visible on all the spectra. This means that the X-rays have been excited only within the film. At higher acceleration voltages, the depth at which the characteristic $\mathrm{X}$-ray excitation occurs is greater. For Sample 1 at the voltage of $7 \mathrm{kV}$ there is an additional peak of silicon originating from the quartz substrate. With higher accelerating voltage $(10 \mathrm{kV}$ and $15 \mathrm{kV})$, the intensity of silicon and oxygen peaks is greater (Fig. 2). The situation is similar for Sample 2, but lower $\operatorname{PdL} \alpha$ peak intensity indicates that the concentration of this element in the film is lower (Fig. 3). In the case of Sample 3, at the voltage of $7 \mathrm{kV}$ the peak of quartz is not visible (Fig. 4). This means that this film has the greatest thickness.

For quantification of components of the film by $\mathrm{X}$-ray microanalysis, the intensity of the peaks corresponding to the constituent elements in the film 


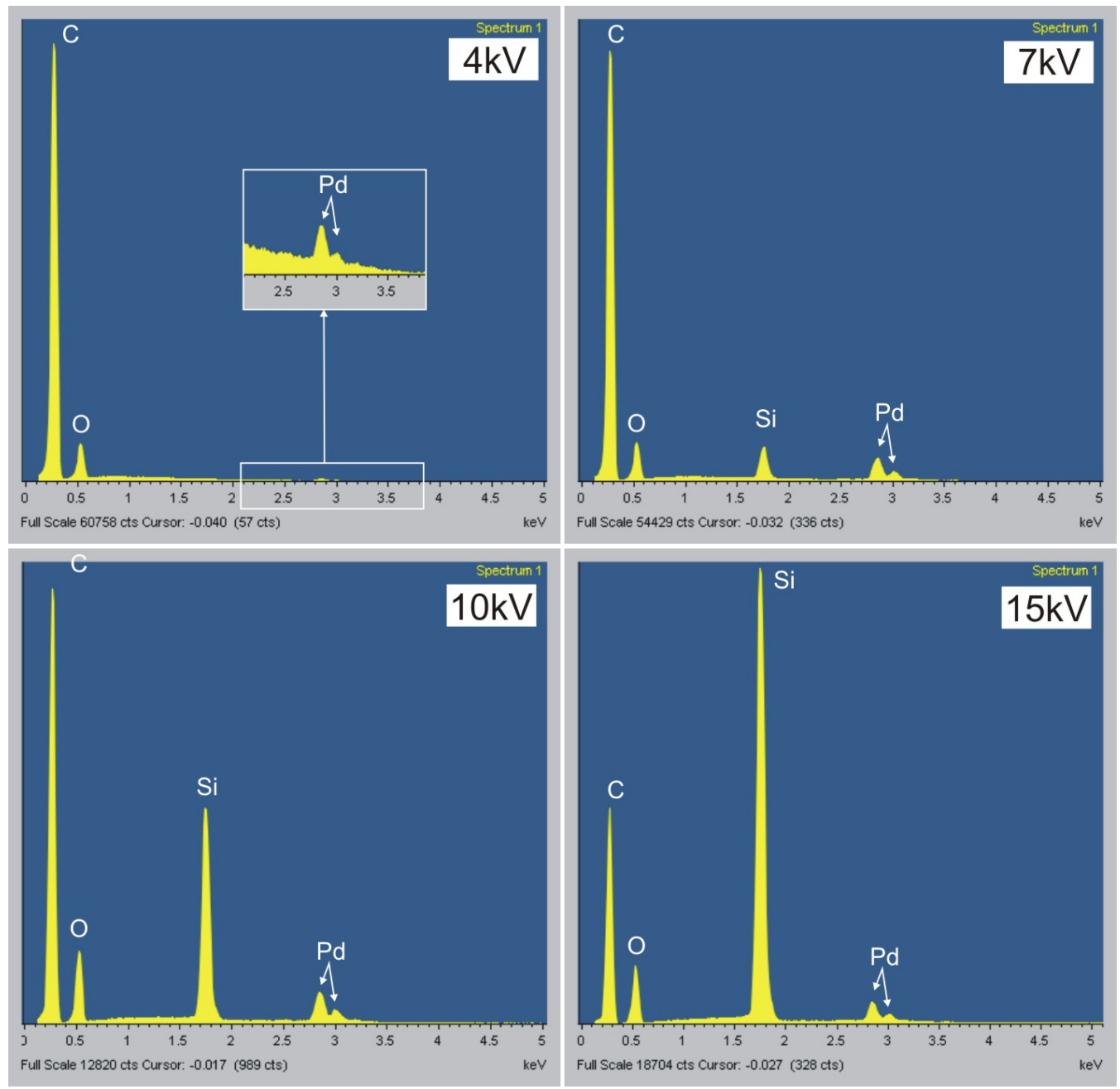

Fig. 2. EDX spectra of Sample 1 at different accelerating voltages.

is proportional to their concentration by weight. The complexity of the interactions of characteristic $\mathrm{X}$-rays with the film components requires that these values were corrected to the actual concentration of these elements. The most common methods of correction in quantitative microanalysis are ZAF and Phi-Rho-Z correction methods [13]. The quantitative microanalysis control method - INCA - is provided with a correction algorithm called "XPP", developed by Pouchou and Pichoir [14], which ensures a high level of confidence of the results.

The quantitative analysis results for the C-Pd films obtained at different accelerating voltages are shown in Table 2 for Sample 1, Table 3 for Sample 2 and Table 4 for Sample 3.
Table 2. The quantitative analysis results for Sample 1.

\begin{tabular}{ccccc}
\hline $\begin{array}{l}\mathbf{U}_{\mathbf{0}}[\mathbf{k V}] \\
\text { [wt.\%] }\end{array}$ & $\mathbf{4}$ & $\mathbf{7}$ & $\mathbf{1 0}$ & $\mathbf{1 5}$ \\
\hline \hline $\mathrm{C}$ & 63.16 & 59.12 & 61.38 & 61.23 \\
$\mathrm{O}$ & 8.94 & 9.55 & 13.18 & 15.36 \\
$\mathrm{Si}$ & - & 4.92 & 13.89 & 19.56 \\
$\mathrm{Pd}$ & 27.90 & 26.41 & 11.54 & 3.86 \\
\hline
\end{tabular}

The results of the quantitative analysis for Samples 1 and 2 carried out at a voltage of $4 \mathrm{kV}$ reflect the actual concentrations of the elements in the films. At a voltage equal to $7 \mathrm{kV}$ the results begin to diverge from the actual concentrations of 

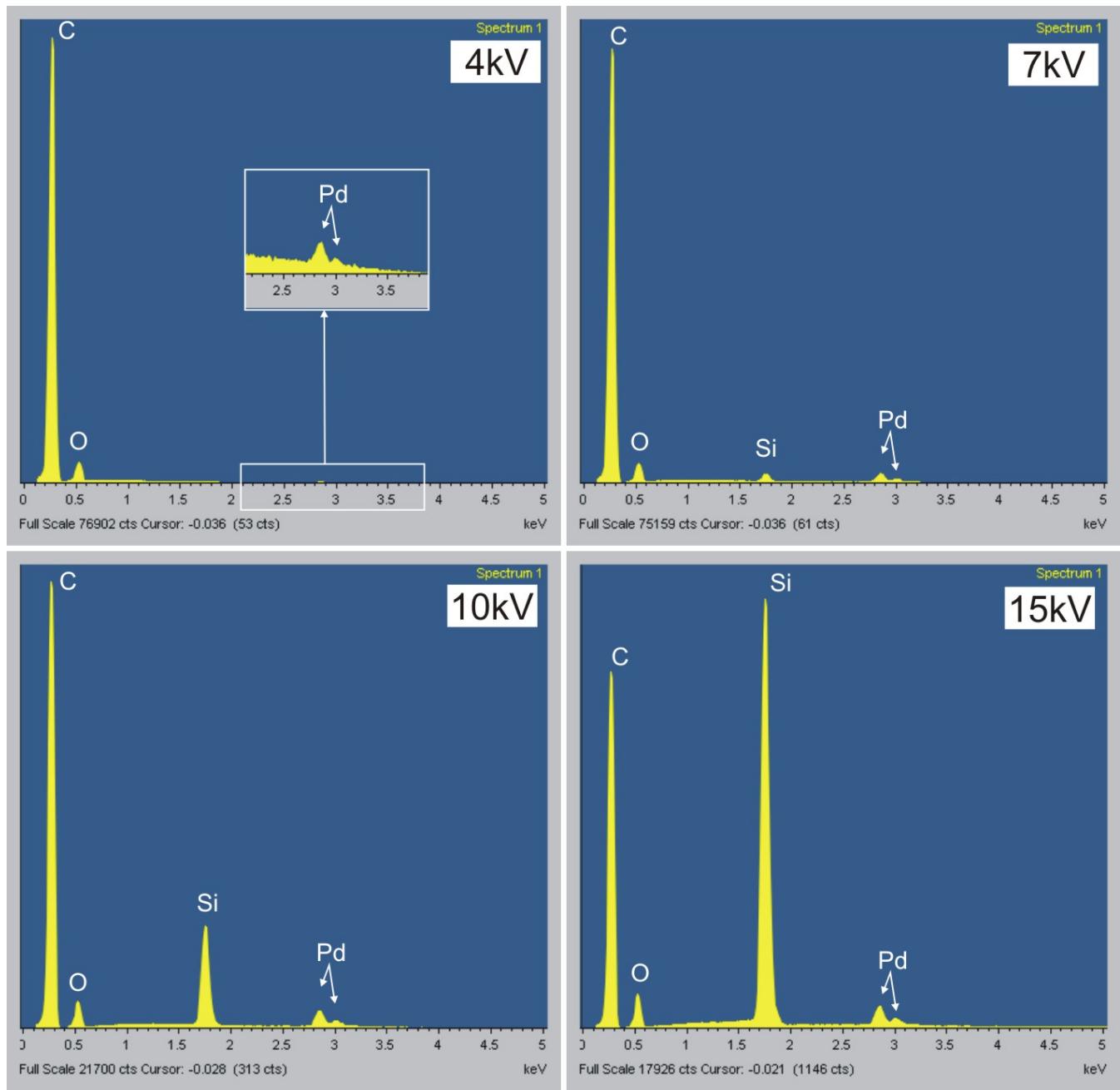

Fig. 3. EDX spectra of Sample 2 at different accelerating voltages.

Table 3. The quantitative analysis results for Sample 2. Table 4. The quantitative analysis results for Sample 3.

\begin{tabular}{ccccc}
\hline $\begin{array}{l}\mathbf{U}_{\mathbf{0}}[\mathbf{k V}] \\
\text { [wt. \%] }\end{array}$ & $\mathbf{4}$ & $\mathbf{7}$ & $\mathbf{1 0}$ & $\mathbf{1 5}$ \\
\hline \hline $\mathrm{C}$ & 77.52 & 75.14 & 73.67 & 71.70 \\
$\mathrm{O}$ & 6.20 & 7.73 & 8.21 & 9.13 \\
$\mathrm{Si}$ & - & 1.66 & 9.31 & 15.85 \\
$\mathrm{Pd}$ & 16.28 & 15.47 & 8.81 & 3.32 \\
\hline
\end{tabular}

\begin{tabular}{lcccc}
\hline $\begin{array}{l}\mathbf{U}_{\mathbf{0}}[\mathbf{k V}] \\
\text { [wt.\%] }\end{array}$ & $\mathbf{4}$ & $\mathbf{7}$ & $\mathbf{1 0}$ & $\mathbf{1 5}$ \\
\hline \hline $\mathrm{C}$ & 68.08 & 81.94 & 80.64 & 79.22 \\
$\mathrm{O}$ & 4.45 & 3.42 & 3.47 & 4.7 \\
$\mathrm{Si}$ & - & - & 2.85 & 10.57 \\
$\mathrm{Pd}$ & 27.48 & 14.64 & 13.04 & 5.52 \\
\hline
\end{tabular}

these elements. When the analysis is carried out at a voltage greater than $4 \mathrm{kV}$, the infinite layer thickness is measured and Pd content is decreasing. The Sample 1 is the thinnest; for a thicker film the accelerating voltages should be different. Composi-

tion of the Sample 3 can be determined at a voltage of $7 \mathrm{kV}$.

The operator should be capable of choosing the most appropriate measurement parameters and correctly interpreting the results because the quantita- 

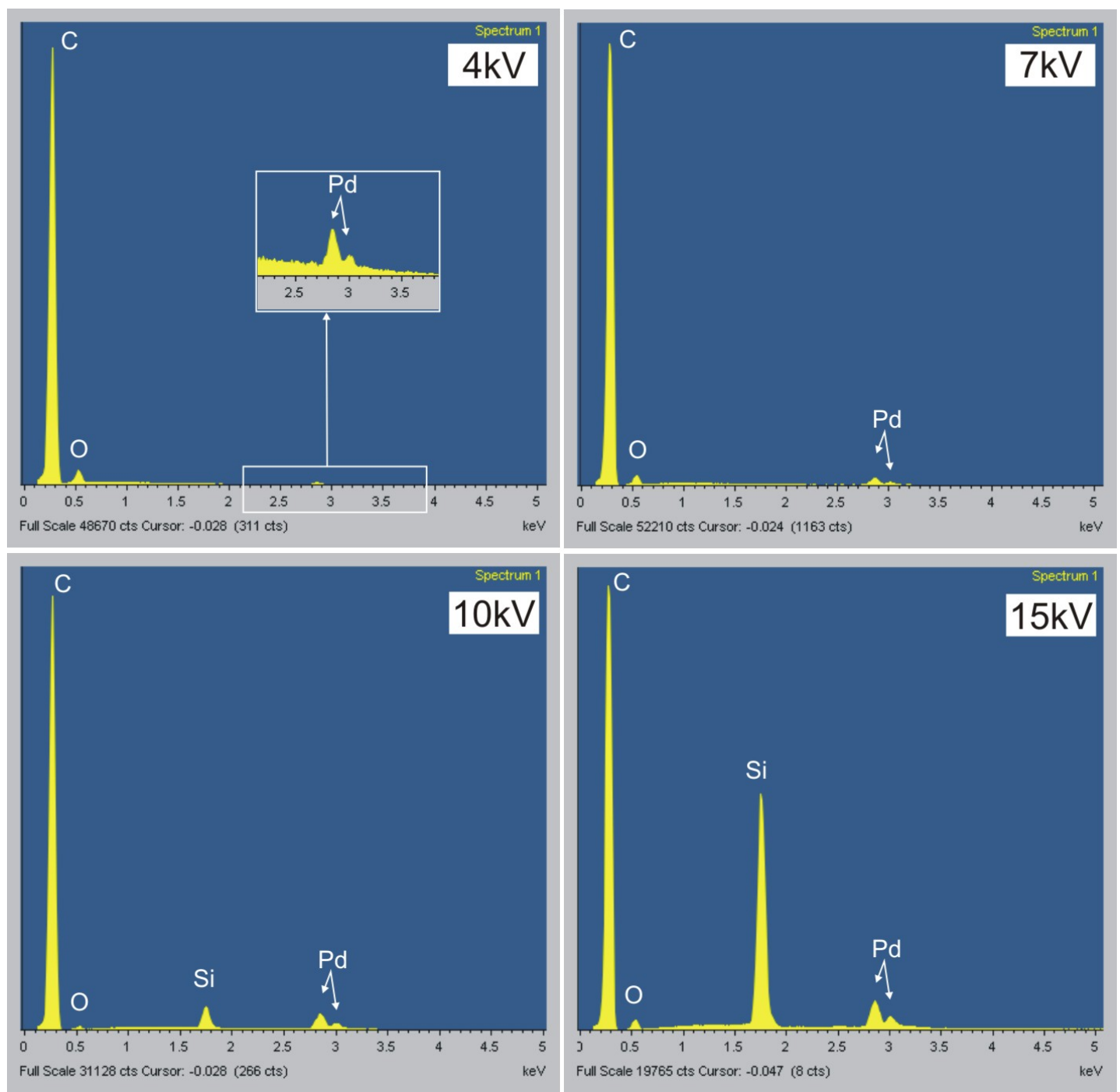

Fig. 4. EDX spectra of Sample 3 at different accelerating voltages.

tive analysis does not include the option of testing the composition of thin films.

Analysis of the results shows that in the case of Samples 1 and 2 a significant difference in the percentage of palladium was obtained when the electron beam penetrated the substrate, i.e. between $7 \mathrm{kV}$ and $10 \mathrm{kV}$ voltage. In the case of Sample 3 we can observe significant differences for the beam energy of $4 \mathrm{kV}$ and $7 \mathrm{kV}$. For both voltages the peak of the quartz is not recorded, both results include only the content of the film. This means that in case of films thicker than $300 \mathrm{~nm}$ (at the appropriate technological parameters of PVD process), during the deposition of C-Pd film on the substrate, segmen- tation of the components of the film takes place. The method of determination of Pd in the carbonpalladium film based on EDX, presented in this article, has enabled the discovery of the phenomenon of self-organisation layers in a film during the deposition.

The multi-layer film composed of carbonpalladium layers and the method of its preparation has been reported by us as a patent application [15].

To illustrate the depth of electron penetration into the investigated material, different accelerating voltages were used for Monte Carlo simulations. For this purpose, CASINO (CArlo 
SImulation of elektroN trajectory in sOlids) software was used [16]. According to the parameters of the model, the film has a thickness of $200 \mathrm{~nm}$.

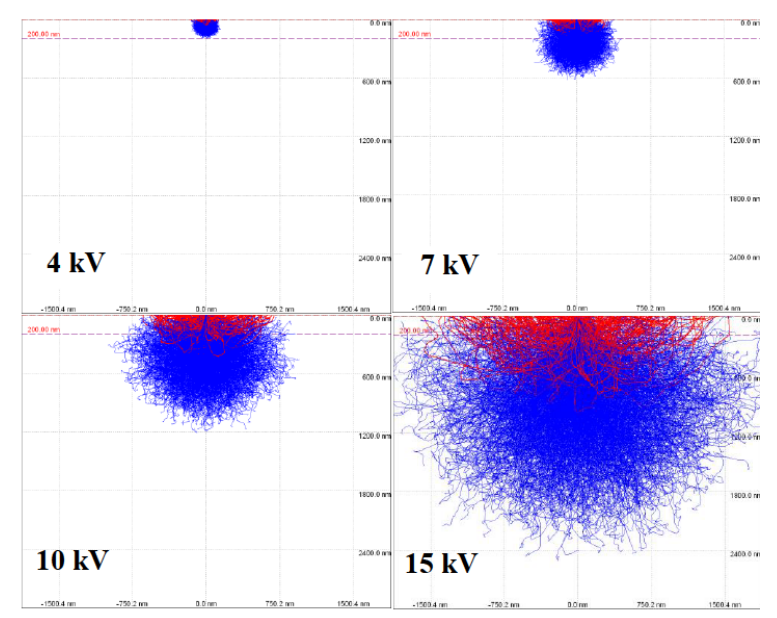

Fig. 5. Simulation paths of electrons in the film at different accelerating voltages (secondary electrons: blue, back-scattered electrons: red).

Results of simulations at different accelerating voltages are shown in Fig. 5. Secondary electrons are shown in blue whereas the back-scattered electrons are shown in red. If the film thickness is $200 \mathrm{~nm}$ (marked in Fig. 5 for each accelerating voltage with a red dashed line) at a voltage of $4 \mathrm{kV}$, all dispersion electrons are confined to the film. The depth of the X-ray excitation is slightly smaller than $200 \mathrm{~nm}$, the image of this simulation confirms the conditions of the actual measurements carried out at a voltage of $4 \mathrm{kV}$. At higher voltages, the stronger the excitation signal from the substrate, which is $\mathrm{SiO}_{2}$, the higher the excitation voltage to accelerate the X-rays. The spectra contain an additional peak originating from $\mathrm{Si}$ with the intensity increasing as the accelerating voltage increases.

\section{Conclusions}

Our research has shown that C-Pd films have different topography and palladium content $(\%)$, depending on the technological conditions of the underlying process. The analysis of thin films by $\mathrm{X}$-ray microanalysis provided information on the thickness of the films.
In all C-Pd samples, the study of accelerating voltage of $4 \mathrm{kV}$ and the characteristic $\mathrm{X}$-ray have been excited only within the film. When the accelerating voltage was increased to $7 \mathrm{kV}$, an additional peak originating from the substrate for Samples 1 and 2 appeared. It means that the thicknesses of these films were smaller than $500 \mathrm{~nm}$ and in this case the substrate was excited. In case of the Sample 3, there was a strong segregation of palladium at the surface of the film, resulting in an increase in its concentration for the measurement at a $4 \mathrm{kV}$ accelerating voltage.

It is not always possible to apply such conditions of the analysis and one should be aware that the results obtained at higher voltages may contain additional peaks originating from the substrate and this gives inaccurate values of concentrations of the film components, and the higher the voltage is applied, the greater the error.

Additionally, our studies show that the morphology of C-Pd films has a major impact on its topography. Differences in topography between the films are clearly visible. The thickest film (Sample 3) with the smallest percentage of palladium has the most developed surface. The composition of this film is not homogeneous at different depths. The thinnest sample with the highest content of palladium (Sample 1) is more uniform and has a smooth surface. Larger palladium content difference with respect to carbon and the increase in thickness of the layer affects the formation of the grains on the surface. It causes the formation of sublayers with increased content of palladium.

\section{Acknowledgements}

This research was co-financed by the European Regional Development Fund within the Innovative Economy Operational Programme 2007 - 2013 (title of the project "Development of technology for a new generation of the hydrogen and hydrogen compounds sensor for applications in above normative conditions" No. UDA-POIG.01.03.01-14-071/08-09).

\section{References}

[1] Efremenko I., J. Mol. Catal. A-Chem., 173 (2001), 19.

[2] PaŁosz B., Composites, 4 (9) (2004), 16.

[3] Dankerta O., Pundt A., Appl. Phys. Lett., 81 (9) (2002), 1618.

[4] Jewell L.L., Davis B.H., Appl. Catal. A-Gen., 310 (2006), 1 . 
[5] Sobczak K., DŁużewski P., Klepka M.T., Kurowska B., Czerwosz E., Int. J. Hydrogen. Energ., 37 (2012), 18556.

[6] Czerwosz E., DŁużewski P., Kowalska E., KozŁowski M., Rymarczy J ., Phys. Status. Solidi. C, $8(7-8)(2011), 2527$.

[7] Kowalska E., Czerwosz E., Kamińska A., KozŁowki A., J. Therm. Anal. Calorim., 108 (2012), 1017.

[8] Asahina S., Togashi T., Terasaki O., Takami S., Adschiri T., Shibata M., ERdMAn N., Microsc. Anal., 11 (2012), 12.

[9] Czerwosz E., Diduszko R., DŁużewski P., KęCZKowska J., KozŁowski M., RYMARCZyK J., SuCHAŃsKa M., Vacuum, 82 (2008), 372.

[10] Rymarczyk J., Czerwosz E., Richter A., Cent. Eur. J. Phys., 9 (2011), 300.

[11] Newbury D.E., J. Res. Natl. Inst. Stan., 107 (2002), 605.
[12] BARBACKI A., Mikroskopia elektronowa, Wydawnictwo Politechniki Poznańskiej, Poznań, 2007.

[13] Lavrent'ev Y.G, Korolyuk V.N., Usova L.V., J. Anal. Chem.+, 59 (2004), 600.

[14] Pouchou J.L., PIChOIR F., Quantitative analysis of homogeneous or stratified microvolumes applying the model "PAP", in: K.F.J. HEINRICH, D. NEWBURY (Eds.), Electron Probe Quantification, Plenum Press, New York and London, 1991, p. 31.

[15] Czerwosz E., Wronka H., RymarczyK J., DŁUŻEWSKI P., Multi-layers film composed of carbonpalladium layers and method of its preparation, Patent No. 406192, 22.11.2013.

[16] http://www.gel.usherbrooke.ca/casino/ index.html.

Received 2013-06-05

Accepted 2014-04-02 